\title{
Mutant mice derived by ICSI of evaporatively dried spermatozoa exhibit expected phenotype
}

\author{
Ming-Wen $\mathrm{Li}^{1}$, Brian Baridon ${ }^{1}$, Amanda Trainor ${ }^{1}$, Esi Djan ${ }^{1}$, Amanda Koehne ${ }^{2}$, \\ Stephen M Griffey ${ }^{2}$, John D Biggers ${ }^{3}$, Mehmet Toner ${ }^{4}$ and K C Kent Lloyd ${ }^{1}$ \\ ${ }^{1}$ Mouse Biology Program and ${ }^{2}$ Comparative Pathology Laboratory, School of Veterinary Medicine, University of \\ California, 2795 Second Street, Suite 400, Davis, California 95616, USA, ${ }^{3}$ Department of Cell Biology, Harvard \\ Medical School, Boston, Massachusetts 02421, USA and ${ }^{4}$ Center for Engineering in Medicine, Massachusetts General \\ Hospital, Harvard Medical School and Shriners Hospital for Children, Boston, Massachusetts 02115, USA
}

Correspondence should be addressed to K C K Lloyd; Email: kclloyd@ucdavis.edu

\begin{abstract}
Apolipoprotein E (Apoe)-deficient knockout mice were used to test the hypothesis that mutant mice preserved as evaporatively dried (ED) spermatozoa, stored at $-80{ }^{\circ} \mathrm{C}$ for 6 months, and then recovered by ICSI will exhibit the same phenotype as before preservation.

The birth rate of mice recovered by ICSI of evaporatively dried spermatozoa was lower than that of fresh spermatozoa (17.5 vs $38.0 \%$ ). Progeny of mice preserved using evaporatively dried spermatozoa were reproductively sound. From these, the second generation of mice produced by natural mating showed lesions typical of APOE deficiency, including severe hypercholesterolemia, hypertriglyceridemia, markedly increased plasma low-density lipoprotein level, and extensive and severe atherosclerotic lesions in the aorta. We conclude that the expected phenotype caused by an induced genetic mutation can be faithfully recapitulated and sustained in subsequent generations of mice preserved and stored as ED spermatozoa and recovered using ICSI. Because it is simpler, faster, and cheaper than conventional (cryopreservation) and nonconventional (freeze-drying) preservation procedures, evaporative drying is a viable, cost-effective, and efficient method for preserving and storing valuable mutant mouse strains.

Reproduction (2012) 143 449-453
\end{abstract}

\section{Introduction}

Because of its ease of application and cost-effectiveness, evaporative drying is an attractive alternative to traditional methods for preserving mouse spermatozoa (McGinnis et al. 2005, Li et al. 2007a, 2007b, Biggers 2009). Spermatozoa preserved and stored under currently available drying techniques have little or no motility post-recovery and thus require artificial reproductive techniques, such as ICSI, to successfully fertilize an oocyte. In earlier studies (Li et al. 2007a, 2007b), we have demonstrated that ICSI using evaporatively dried (ED) spermatozoa after storage at -20 and $-80^{\circ} \mathrm{C}$ for up to 5 months from wild-type mouse strains on a variety of genetic backgrounds, including B3C3F1, C57BL/6, and $\mathrm{FVB} / \mathrm{N}$, can be used to derive liveborn, healthy, and reproductively sound offspring.

Although other preservation and storage methods for embryos and spermatozoa, such as cryopreservation, are equally effective, they are far less cost-effective than evaporative drying. The creation and development of thousands of new mutant mouse strains over the next several years (Collins et al. 2007) will overwhelm the available time required to perform embryo cryopreservation and the financial resources for preserving and storing frozen embryos and spermatozoa. On the other hand, evaporative drying is not only facile but also rapid and low cost, and dried spermatozoa can be archived and shipped under far less expensive storage conditions (e.g. -80 or $4{ }^{\circ} \mathrm{C}$ ). To date, however, there have been no studies to validate the use of evaporative drying technology to preserve, store, and recover spermatozoa from genetically modified mouse strains. Further, no studies have demonstrated the fidelity of recovery of a mutant phenotype in genetically altered mice, such as knockout mice, derived by ICSI of ED spermatozoa. Sperm DNA or gene integrity is essential to cryopreservation of genetically modified mouse strains, but sperm cryopreservation has been reported to increase DNA or chromosome damage in equine (Linfor \& Meyers 2002), monkey (Li et al. 2007 C), boar (Hu et al. 2008), and chicken (Gliozzi et al. 2011).

Therefore, the purpose of this study was to determine the extent to which evaporative drying of spermatozoa is a viable option for preserving, archiving, and 
Table 1 Development of first generation of $A p o e^{-/-}$mice by ICSI.

\begin{tabular}{lcc}
\hline & $\begin{array}{c}\text { Fresh } \\
\text { spermatozoon } \\
\text { group }\end{array}$ & $\begin{array}{c}\text { ED } \\
\text { spermatozoon } \\
\text { group }\end{array}$ \\
\hline No. of oocytes injected & 380 & 364 \\
No. of oocytes survived ICSI & 149 & 128 \\
ICSI survival rate (\%) & 39.2 & 35.2 \\
No. of two-cell embryos & 137 & 114 \\
$\quad$ obtained & 91.9 & 89.1 \\
Fertilization rate (\%) & 52 & 20 \\
No. of pups born & 38.0 & $17.5^{*}$ \\
Birth rate (\%) & $25 / 27$ & $12 / 8$ \\
Sex ratio (M/F) & & \\
\hline
\end{tabular}

ED, evaporatively dried. All ICSI-derived two-cell embryos were transferred for production of pups; ICSI survival rate (\%), number of oocytes survived ICSI/number of injected oocytes; fertilization rate (\%), number of two-cell embryos/number of oocytes survived ICSI; birth rate $(\%)$, number of pups born/number of two-cell embryos transferred. *Significantly different from the value in the same row $(P<0.001)$.

reconstituting mutant mouse strains. To do so, we ED, stored, and recovered spermatozoa from apolipoprotein E-deficient $\left(A p o e^{-/-}\right)$knockout mice (Piedrahita et al. 1992, Plump et al. 1992, Zhang et al. 1992, Reddick et al. 1994), the most widely used atherosclerosis mouse model (Breslow 1996, Whitman 2004). Because APOE is an integral plasma lipoprotein, a genetic deletion (knockout) mutation specific to the Apoe gene in mice causes significant alterations in lipid metabolism and plasma lipid and lipoprotein profiles, which confers a spontaneous susceptibility to early and extensive development of atherosclerosis regardless of diet. Apoe $^{-1-}$ knockout mice exhibit severe hypercholesterolemia, hypertriglyceridemia, markedly increased levels of low-density lipoprotein (LDL), and arterial atherosclerosis (Piedrahita et al. 1992, Plump et al. 1992, Zhang et al. 1992, Reddick et al. 1994, Breslow 1996, Whitman 2004). Further, to verify whether evaporative drying of sperm alters the expected mutant phenotype, we conducted a pathophysiological analysis of the primary abnormalities in Apoe ${ }^{-/-}$mutant mice recovered from ED spermatozoa, and compared our findings to the well-characterized pathology expected in this mutant mouse strain.

\section{Results \\ Development of first generation of $\mathrm{Apoe}^{-/-}$mice by ICSI}

After 6 months storage at $-80^{\circ} \mathrm{C}$, ED spermatozoa were successfully used for ICSI to fertilize oocytes at a rate similar to that of fresh spermatozoa (Table 1). No difference was found in either ICSI survival rates or fertilization rates (two-cell rate) in the ED group compared with the fresh spermatozoon group $(P>0.05)$. However, the birth rate of transferred embryos in the ED group was significantly lower that that of the fresh spermatozoon group $(P<0.05)$.

\section{Development of second generation of $\mathrm{Apoe}^{-/-}$mice by natural mating}

Apoe ${ }^{-/-}$mice derived by ICSI using fresh spermatozoa were reproductively sound (Table 2). All five breeding pairs produced at least one litter each (litter rate 100\%). In contrast, Apoe ${ }^{-1-}$ mice derived by ICSI using the ED spermatozoa seemed less reproductively sound. Out of six breeding pairs, five produced at least one litter each (litter rate $83.3 \%$ ), which was lower than that of the fresh spermatozoon group (litter rate 100\%), but the difference was not significant $(P>0.05)$.

\section{Plasma lipid profile analysis}

The plasma levels of total cholesterol, triglycerides, and LDL are shown in Figs 1, 2 and 3, respectively. Total cholesterol levels of second-generation mice in the fresh Apoe ${ }^{-/-}$spermatozoon group $(559 \pm 44 \mathrm{mg} / \mathrm{dl}, n=10)$ and ED spermatozoon group ( $518 \pm 24 \mathrm{mg} / \mathrm{dl}, n=10)$ were about eight times higher than that of the wild-type (nonmutant) control group $(67 \pm 1 \mathrm{mg} / \mathrm{dl}, \quad n=10$; $P<0.0001$ ) (Fig. 1). These results were characteristic of the severe hypercholesterolemia phenotype observed in $A_{p o e^{-/-}}$knockout mice. There was no difference in total cholesterol level between fresh spermatozoon and ED spermatozoon groups $(P=0.42)$, which confirmed that evaporative drying and $-80^{\circ} \mathrm{C}$ storage for 6 months did not alter or modify the expected mutant Apoe ${ }^{-/-}$phenotype.

Mice in both the fresh and ED spermatozoon groups had severe hypertriglyceridemia (Fig. 2). Triglyceride levels were $59 \pm 6 \mathrm{mg} / \mathrm{dl}(n=10)$ in the fresh spermatozoon group and $47 \pm 6 \mathrm{mg} / \mathrm{dl}(n=10)$ in the ED spermatozoon group, both of which were significantly higher than that of wild-type control mice $(19 \pm 1 \mathrm{mg} / \mathrm{dl}, n=10 ; P<0.001)$. There was no significant difference in triglyceride level between fresh and ED spermatozoon groups $(P=0.16)$.

We measured a markedly increased level of $L D L$ in both the fresh spermatozoon group $(416 \pm 30 \mathrm{mg} / \mathrm{dl}, n=10)$ and the ED spermatozoon group $(373 \pm 16 \mathrm{mg} / \mathrm{dl}, n=10)$ (Fig. 3). These levels were 46 and 41 times higher, respectively, than the trace level $(9 \pm 1 \mathrm{mg} / \mathrm{dl}, n=10$, $P<0.0001$ ) measured in the wild-type control mice. There was no significant difference in LDL level between the fresh and ED spermatozoon groups $(P>0.05)$.

Table 2 Development of second generation of $\mathrm{Apoe}^{-/-}$mice by natural mating.

\begin{tabular}{lcc}
\hline & $\begin{array}{c}\text { Fresh } \\
\text { spermatozoon } \\
\text { group }\end{array}$ & $\begin{array}{c}\text { ED } \\
\text { spermatozoon } \\
\text { group }\end{array}$ \\
\hline No. of natural mating pairs & 5 & 6 \\
No. of litters born & 5 & 5 \\
Litter rate (\%) & 100 & 83.3 \\
No. of pups born & 30 & 28 \\
Sex ratio (M/F) & $14 / 16$ & $17 / 11$
\end{tabular}

ED, evaporatively dried; litter rate (\%), number of litters born/number of breeding pairs. There are no significant differences between these groups. 


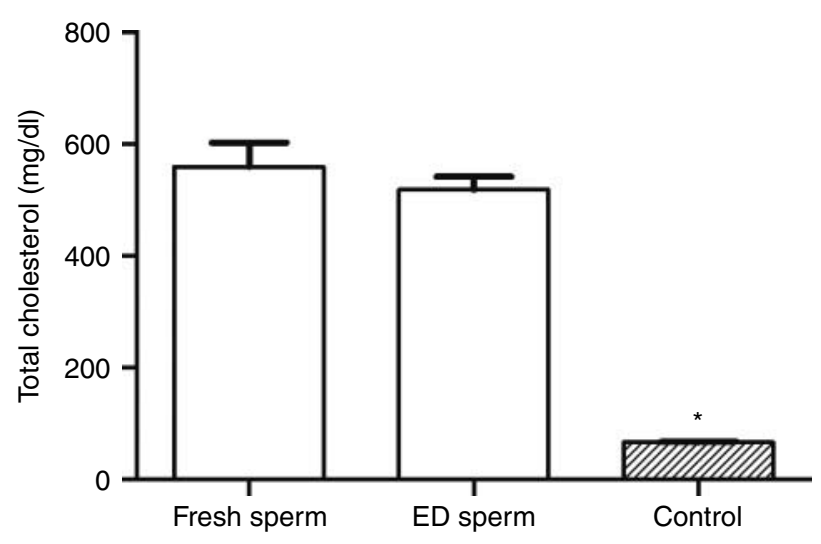

Figure 1 The plasma total cholesterol levels of the second-generation mice in the fresh and evaporatively dried (ED) Apoe ${ }^{-/-}$spermatozoon groups compared with that of the control group mice. ${ }^{*} P<0.0001$ compared with that of fresh spermatozoon group or ED spermatozoon group.

\section{Histopathological analysis}

Histopathological evidence of types I-V atherosclerosis was identified in all mutant mice (Table 3 ). In the fresh and ED spermatozoon groups, $90-100 \%$ of the mice had atherosclerotic lesions of which $60-70 \%$ were advanced types IV-V lesions. In contrast, only $20 \%$ of the control wild-type group had lesions, all of which were mild precursor types I and II lesions.

\section{Discussion}

After 6 months storage at $-80^{\circ} \mathrm{C}$, ED spermatozoa were able to fertilize oocytes by ICSI at a rate similar to that of fresh spermatozoa (Table 1). Our results are consistent with those we reported previously using ED spermatozoa from wild-type B6C3F1 (Li et al. 2007a) and C57BL/6 and $\mathrm{FVB} / \mathrm{N}$ strains (Li et al. 2007b). However, we found that the birth rate of transferred embryos in the ED group was significantly lower than that of the fresh spermatozoon group $(P<0.05)$. Although lower birth rates of embryos derived from ED spermatozoa were not observed in wild-type B6C3F1 (Li et al. 2007a) and $\mathrm{C} 57 \mathrm{BL} / 6$ and $\mathrm{FVB} / \mathrm{N}$ strains (Li et al. 2007b), storage times in those studies (1-5 months) were less than that in the current study (6 months).

While it is possible that the Apoe mutation itself may contribute to spermatozoon deterioration during storage at $-80{ }^{\circ} \mathrm{C}$, it is more likely that the deterioration is associated with the long-term storage at $-80^{\circ} \mathrm{C}$ and not the evaporative drying procedure itself. Our previous studies (McGinnis et al. 2005, Li et al. 2007a) demonstrated that mouse embryos derived from ED sperm after blow-drying of nitrogen gas for 5 to $6 \mathrm{~min}$ at a flow rate of $10 \mathrm{l} / \mathrm{min}$ can develop in vitro to the blastocyst stage at a high rate $(70-80 \%)$. Further, the developmental potential of ED spermatozoa did not decrease in the first month of storage at $4,-20$ or $-80^{\circ} \mathrm{C}$. Thus, the biological potential of embryos derived from ED spermatozoa to develop into blastocysts in vitro is progressively impaired as storage time is increased (McGinnis et al. 2005, Li et al. 2007a).

Severe hypercholesterolemia, severe hypertriglyceridemia, markedly increased LDL level, and extensive severe atherosclerotic lesions in the aorta are characteristics of the Apoe phenotype in Apoe knockout mice (Piedrahita et al. 1992, Plump et al. 1992, Zhang et al. 1992, Reddick et al. 1994, Breslow 1996, Whitman 2004). We found that this phenotype could be faithfully recapitulated in Apoe mice recovered by ICSI of ED spermatozoa after storage at $-80{ }^{\circ} \mathrm{C}$ for 6 months. The observed increased plasma cholesterol, triglyceride, and LDL levels and histopathological evidence for atherosclerosis are pathognomonic for APOE deficiency. Further, this phenotype was identical to that in mice rederived by ICSI of fresh spermatozoa, indicating that the drying technique and storage at $-80{ }^{\circ} \mathrm{C}$ had no untoward impact on the expected phenotype. Finally, none of these phenotypic changes were observed in control wild-type C57BL/6N mice, which indicated that the mutant phenotype was not elicited by the ICSI procedure itself. To our knowledge, this is the first published evidence verifying the fidelity of recovery of the expected mutant phenotype and confirmation that no unexpected abnormalities occurred in mice derived from ICSI using ED spermatozoa after prolonged cold storage.

\section{Materials and Methods}

\section{Animals}

Male and female homozygous Apoe ${ }^{-1-}$ mice (B6.129P2Apoe $^{\mathrm{tm} 1 \mathrm{UncN} 11 \mathrm{C} 57 \mathrm{BL} / 6 \mathrm{~N})}$ and wild-type $\mathrm{C} 57 \mathrm{BL} / 6 \mathrm{~N}$ mice were purchased from Taconic Corporate (Hudson, NY, USA). All mice were fed on normal diets from LabDiet (Richmond, IN, USA) and housed in a specific pathogen-free vivarium with a $14 \mathrm{~h}$ on/10 h off light cycle before use. Euthanasia was performed by a combination of $\mathrm{CO}_{2}$ asphyxiation followed by cervical dislocation. The care, use, and disposition of all

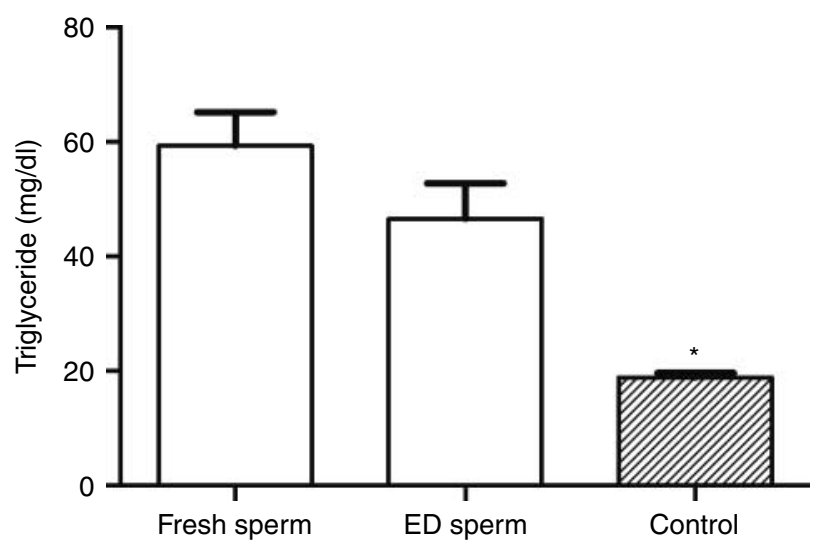

Figure 2 The plasma triglyceride levels of the second-generation mice in the fresh and evaporatively dried (ED) Apoe ${ }^{-1-}$ spermatozoon groups compared with that of the control group mice. ${ }^{*} P<0.001$ compared with that of fresh spermatozoon group or ED spermatozoon group. 


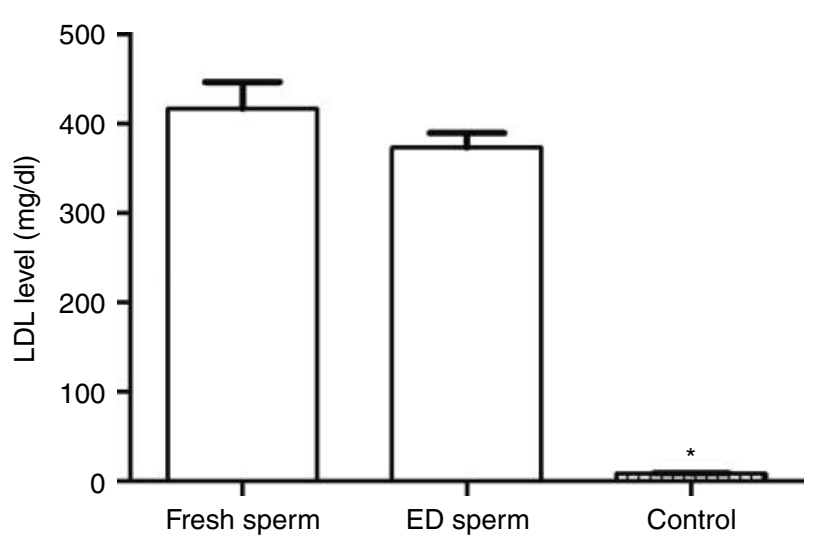

Figure 3 The plasma low-density lipoprotein (LDL) levels of the secondgeneration mice in the fresh and evaporatively dried (ED) Apoe ${ }^{-/-}$ spermatozoon groups compared with that of the control group mice. ${ }^{*} P<0.0001$ compared with that of fresh spermatozoon group or ED spermatozoon group.

mice used in this study were reviewed and approved by the Institutional Animal Care and Use Committee of the University of California at Davis.

\section{Spermatozoon collection and evaporative drying}

Spermatozoa were collected from both cauda epididymides of each of 5 Apoe $^{-/-}$knockout male mice. After harvest, spermatozoa were divided into two groups: spermatozoa in the fresh spermatozoon group were used for ICSI immediately and spermatozoa in the ED group were ED using a previously published method (Li et al. 2007b). Briefly, spermatozoa were collected and gently mixed in warm Na-K-EGTA medium ( $\mathrm{pH}$ 8.2). Then, $100 \mu \mathrm{l}$ of this spermatozoon suspension was mixed with an equal volume of $25 \mu \mathrm{g} / \mathrm{ml} \alpha$-hemolysin (Sigma) in buffered saline solution containing $0.01 \mathrm{~mol} / \mathrm{l}$ $\mathrm{NaCl}, 0.12 \mathrm{~mol} / \mathrm{I} \mathrm{KCl}, 0.005 \mathrm{~mol} / \mathrm{l}$ glucose, and $0.02 \mathrm{~mol} / \mathrm{l}$ 4-(2-hydroxyethyl)-1-piperazineethanesulfonic acid, $\mathrm{pH} 7.4$, at room temperature $\left(22-25^{\circ} \mathrm{C}\right)$ in the dark to permeabilize spermatozoa. After $30 \mathrm{~min}, 200 \mu \mathrm{l}$ of $1.0 \mathrm{~mol} / \mathrm{l}$ trehalose in Na-K-EGTA medium was added (final concentration of trehalose $0.5 \mathrm{~mol} / \mathrm{l}$ ) to the spermatozoon suspension that was mixed, and allowed to incubate for $15 \mathrm{~min}$ at room temperature in the dark. After trehalose loading, $20 \mu \mathrm{l}$ aliquots of spermatozoon suspensions were placed within a $10-\mathrm{mm}$ circular area demarcated on a sterile glass slide (Ted Pella, Redding, CA, USA). The slide was placed into a drying chamber where a continuous stream of compressed ultrapure-grade nitrogen gas (Airgas, Sacramento, CA, USA) was blown directly across the spermatozoon sample for $6 \mathrm{~min}$ at a flow rate of $10 \mathrm{l} /$ min. Afterward, spermatozoa were vacuum-sealed using an MPV-18 Mighty Mutt vacuum sealer (Impak Corporation, Los Angeles, USA) and stored at $-80{ }^{\circ} \mathrm{C}$ for 6 months before ICSI.

\section{ICSI and embryo transfer}

In the fresh spermatozoon group, spermatozoa from Apoe ${ }^{-/-}$ males were used immediately after collection for ICSI. In the ED group, after 6 months storage at $-80{ }^{\circ} \mathrm{C}, A p o e^{-/-}$ spermatozoa were warmed to $37^{\circ} \mathrm{C}$ for $3 \mathrm{~min}$ and rehydrated with $20 \mu$ of BSA-free FHM medium (Millipore, Billerica, MA, USA) containing $0.01 \%(\mathrm{w} / \mathrm{v})$ polyvinyl alcohol (Sigma) before ICSI. For both groups, female Apoe ${ }^{-/-}$mice (6-10 weeks of age) were superovulated by i.p. injection of $5 \mathrm{IU}$ pregnant mare's serum gonadotropin followed by i.p. injection of $5 \mathrm{IU}$ human chorionic gonadotropin 47-48 h later. The ICSI method used was the same as described previously (Li et al. 2007 b).

ICSI-derived embryos at the two-cell stage were transferred into the oviducts of pseudopregnant $\mathrm{CD} 1$ recipients 0.5 day post coitum and anesthetized with 1.25\% 2,2,2-tribromoethanol (Avertin). After surgery, $0.1 \mathrm{ml}$ of Buprenex $(0.03 \mathrm{mg} / \mathrm{ml}$; Western Medical Supply, Inc., Arcadia, CA, USA) was administered subcutaneously in the flank of each mouse to provide postoperative analgesia. Recipients were kept warm on a heating pad until fully recovered from anesthesia.

All pregnant recipients were allowed to go to term and give birth. When the progeny were 8 weeks old, 1 male and 1 female mouse in the first generation from each litter within a group were chosen randomly as breeding pairs for natural mating to produce the second generation. At 6-7 months of age, mice were analyzed for plasma lipids, lipoproteins in blood, and for atherosclerotic lesions by histopathology. Age-matched wild-type $\mathrm{C} 57 \mathrm{BL} / 6 \mathrm{~N}$ mouse controls were housed in the same vivarium on the same diet.

\section{Analysis of plasma lipid and lipoprotein profiles}

Apoe $^{-1-}$ mice (five males and five females) at 3 months of age from the second generation in both the fresh and ED spermatozoon groups were chosen randomly and fasted for $24 \mathrm{~h}$. Anesthesia was induced using $1.25 \%$ Avertin for the collection of blood samples by cardiocentesis. Blood samples were mixed with $10 \mu \mathrm{l}$ of $0.5 \mathrm{~mol} / \mathrm{I}$ EDTA and centrifuged at $18500 \mathrm{~g}$ at $4{ }^{\circ} \mathrm{C}$ for $10 \mathrm{~min}$ to separate plasma. Plasma aliquots were stored at $-80^{\circ} \mathrm{C}$ before analysis of plasma lipid and lipoprotein profiles. Plasma total cholesterol, triglycerides, and LDL levels were measured using enzymatic colorimetric methods and a Roche Diagnostics COBAS Integra 400 Plus Chemistry Analyzer optimized for rodent blood analysis. Commercial calibrators and control material manufactured by Roche Diagnostics especially for this analyzer system were used to verify performance of the analyzer before every run. Agematched wild-type C57BL/6N mice (five males and five females) were used as controls for plasma lipids and lipoprotein analysis.

Table 3 Development of atherosclerotic lesions in the three experimental groups of mice.

\begin{tabular}{lcccc}
\hline $\begin{array}{l}\text { Experimental } \\
\text { group }\end{array}$ & $\begin{array}{c}\text { No. of mice } \\
\text { examined } \\
(\mathrm{M} / \mathrm{F})\end{array}$ & $\begin{array}{c}\text { Mice with } \\
\text { atherosclerotic } \\
\text { lesions }(\%)\end{array}$ & $\begin{array}{c}\text { Lesion } \\
\text { types }\end{array}$ & $\begin{array}{c}\text { Mice with } \\
\text { lesion } \geq \\
\text { type IV }(\%)\end{array}$ \\
\hline $\begin{array}{l}\text { Fresh } \\
\text { spermatozoon }\end{array}$ & $10(5 / 5)$ & 100 & I to V & 70 \\
$\begin{array}{l}\text { ED } \\
\text { spermatozoon }\end{array}$ & $10(5 / 5)$ & 90 & II to V & 60 \\
Control & $10(5 / 5)$ & 20 & I to II & 0 \\
\hline
\end{tabular}

$M$, male; F, female; ED, evaporatively dried. 


\section{Histopathological analysis}

Histopathology was performed on five male and five female Apoe ${ }^{-/-}$mice, aged 6-7 months, from the second generation in both the fresh and ED spermatozoon groups. Mice were anesthetized with isoflurane and perfused via the left ventricle with $0.9 \% \mathrm{NaCl}$ followed by fixation in $10 \%$ neutral buffered formalin overnight. Following fixation, the aortic perivascular adipose tissue was removed. The aortic root was crosssectioned and the portion of the ascending aorta was longitudinally sectioned. Samples embedded in paraffin, and sectioned at $4 \mu \mathrm{m}$ thickness using a microtome. For each animal, serial aortic sections were mounted on slides and stained with hematoxylin and eosin. Age-matched wild-type $\mathrm{C} 57 \mathrm{BL} / 6 \mathrm{~N}$ mice (five males and five females) were used as controls for histopathological analysis.

Atherosclerotic lesions were classified into types I-VI based on the American Heart Association classification of human atherosclerotic lesions (Stary et al. 1995). In humans, type I-III lesions are precursor lesions that are clinically silent and type IV and $\mathrm{V}$ lesions are advanced and may produce clinical signs. Type I is an initial lesion of isolated macrophage foam cells. Type II is a fatty streak lesion with mainly intracellular lipid accumulation. A type III lesion has the features of a type II lesion with the addition of small extracellular lipid pools. Type IV lesions are atheromas with a core of extracellular lipid. Type $\mathrm{V}$ lesions are fibroatheromas with a lipid core and fibrotic layer, or multiple lipid cores and fibrotic layers, or mainly calcific, or mainly fibrotic lesions. A type VI lesion includes a surface defect with a hematoma, hemorrhage, or a thrombus.

\section{Statistical analysis}

GraphPad Prism 5 software (GraphPad Software, Inc., San Diego, CA, USA) was used for statistical analysis. Data of ICSI survival rates, fertilization rates, and pup birth rates were analyzed by Fisher's exact probability test. Data of plasma levels of total cholesterol, triglycerides, and LDL were analyzed by two-way ANOVA followed by Student's $t$-tests. Continuous variables are presented as mean \pm S.E.M., and $P<0.05$ was chosen as an indication of statistical significance.

\section{Declaration of interest}

The authors declare that there is no conflict of interest that could be perceived as prejudicing the impartiality of the research reported.

\section{Funding}

This project was supported by grants R24 RR018934 and U42 RR014905 from the National Center for Research Resources (NCRR), a component of the National Institutes of Health $(\mathrm{NIH})$. This project was also supported by the UC Davis Mouse Biology Program.

\section{References}

Biggers JD 2009 Evaporative drying of mouse spermatozoa. Reproductive BioMedicine Online 19 (Suppl 4) 4338.

Breslow JL 1996 Mouse models of atherosclerosis. Science 272 685-688. (doi:10.1126/science.272.5262.685)

Collins FS, Rossant J \& Wurst WA 2007 A mouse for all reasons: The International Mouse Knockout Consortium. Cell 128 9-13. (doi:10.1016/ j.cell.2006.12.018)

Gliozzi TM, Zaniboni L \& Cerolini S 2011 DNA fragmentation in chicken spermatozoa during cryopreservation. Theriogenology 75 1613-1622. (doi:10.1016/j.theriogenology.2011.01.001)

Hu JH, Li QW, Jiang ZL \& Li WY 2008 Effects of different extenders on DNA integrity of boar spermatozoa following freezing-thawing. Cryobiology 57 257-262. (doi:10.1016/j.cryobiol.2008.09.004)

Li MW, Biggers JD, Elmoazzen HY, Toner M, McGinnis L \& Lloyd KC 2007 a Long-term storage of mouse spermatozoa after evaporative drying. Reproduction 133 919-929. (doi:10.1530/REP-06-0096)

Li MW, Biggers JD, Toner M, Griffey SM \& Lloyd KC 2007b Phenotypic analysis of $\mathrm{C} 57 \mathrm{BL} / 6 \mathrm{~J}$ and $\mathrm{FVB} / \mathrm{NJ}$ mice generated using evaporatively dried spermatozoa. Comparative Medicine 57 469-475.

Li MW, Meyers S, Tollner TL \& Overstreet JW 2007c Damage to chromosomes and DNA of rhesus monkey sperm following cryopreservation. Journal of Andrology 28 493-501. (doi:10.2164/jandrol.106. 000869)

Linfor JJ \& Meyers SA 2002 Detection of DNA damage in response to cooling injury in equine spermatozoa using single-cell gel electrophoresis. Journal of Andrology 23 107-113.

McGinnis LK, Zhu L, Lawitts JA, Bhowmick S, Toner M \& Biggers JD 2005 Mouse sperm desiccated and stored in trehalose medium without freezing. Biology of Reproduction 73 627-633. (doi:10.1095/biolreprod. 105.042291)

Piedrahita JA, Zhang SH, Hagaman JR, Oliver PM \& Maeda N 1992 Generation of mice carrying a mutant apolipoprotein E gene inactivated by gene targeting in embryonic stem cells. PNAS 89 4471-4475. (doi:10. 1073/pnas.89.10.4471)

Plump AS, Smith JD, Hayek T, Aalto-Setälä K, Walsh A, Verstuyft JG, Rubin EM \& Breslow JL 1992 Severe hypercholesterolemia and atherosclerosis in apolipoprotein E-deficient mice created by homologous recombination in ES cells. Cell 71 343-353. (doi:10.1016/00928674(92)90362-G)

Reddick RL, Zhang SH \& Maeda N 1994 Atherosclerosis in mice lacking Apo E. Evaluation of lesional development and progression. Arteriosclerosis, Thrombosis, and Vascular Biology 14 141-147. (doi:10.1161/ 01.ATV.14.1.141)

Stary HC, Chandler AB, Dinsmore RE, Fuster V, Glagov S, Insull W Jr, Rosenfeld ME, Schwartz CJ, Wagner WD \& Wissler RW 1995 A definition of advanced types of atherosclerotic lesions and a histological classification of atherosclerosis. A report from the Committee on Vascular Lesions of the Council on Arteriosclerosis, American Heart Association. Arteriosclerosis, Thrombosis, and Vascular Biology 15 1512-1531. (doi:10.1161/01.ATV.15.9.1512)

Whitman SC 2004 A practical approach to using mice in atherosclerosis research. Clinical Biochemist Reviews 25 81-93.

Zhang SH, Reddick RL, Piedrahita JA \& Maeda N 1992 Spontaneous hypercholesterolemia and arterial lesions in mice lacking apolipoprotein E. Science 258 468-471. (doi:10.1126/science.1411543)

Received 4 January 2012

First decision 20 January 2012

Accepted 20 January 2012 